Article

\title{
The Exclusionary Practices of Youth Sport
}

\author{
Bethan C. Kingsley* and Nancy Spencer-Cavaliere \\ Faculty of Physical Education and Recreation, University of Alberta, Edmonton, AB, T6G 2H9, Canada; \\ E-Mails: bethan.kingsley@ualberta.ca (B.C.K.), ncavalie@ualberta.ca (N.S.-C.) \\ * Corresponding author
}

Submitted: 14 July 2014 | In Revised Form: 10 January 2015 | Accepted: 14 January 2015 |

Published: 25 June 2015

\begin{abstract}
Youth who live with lower incomes are known to experience social exclusion in a range of social settings, including sport. Despite efforts to reduce financial constraints to participation, increasing opportunities in these ways has not led to increased involvement. There is a need to move beyond a discussion about barriers and explore the quality of young people's engagement within sport. The present study consequently sought to understand the sport involvement of young people living with lower incomes. Interpretive description informed the analysis of transcripts generated from interviews with ten youth (aged 13-18 years) and six parents. Three themes captured the ways income had a prominent influence on the sports involvement of young people. Sports settings generally required that young people acquire abilities from an early age and develop these concertedly over time. The material circumstances in which youth were brought up impacted the extent to which they could or wanted to participate in these ways. The final theme outlines the experiences of young people in sport when they possessed less cultural capital than others in the field. The findings of the study collectively highlight a number of interconnected exclusionary processes in sport and demonstrate the need to reimagine sport in ways that challenge the hegemonic discourses continuing to exclude a large number of young people.
\end{abstract}

\section{Keywords}

ability; cultural capital; exclusion; low-income; sport; youth

Issue

This article is part of the special issue "Sport for Social Inclusion: Critical Analyses and Future Challenges", edited by Dr. Reinhard Haudenhuyse (Vrije Universiteit Brussel, Belgium) and Professor Marc Theeboom (Vrije Universiteit Brussel, Belgium).

(C) 2015 by the authors; licensee Cogitatio (Lisbon, Portugal). This article is licensed under a Creative Commons Attribution 4.0 International License (CC BY).

\section{Introduction}

Sport has been used as a tool to address the social exclusion of young people ${ }^{1}$ in wider policy agendas (Collins \& Kay, 2003; Dagkas \& Armour, 2012). Social exclusion has been defined generally as occurring when individuals are unable to participate in relationships and activities due to a lack of resources, rights and ser-

1 The terms "young people" and "youth" are used synonymously and interchangeably (Dagkas \& Armour, 2012) to describe individuals between the ages of 13 and 18 years, as defined by the practice-based partners in the study. vices (Levitas at al., 2007). Hailed for its capacity to provide opportunities for connection and belonging, sport is positioned as having the potential to mitigate some aspects of social exclusion and engage young people who may be excluded in other areas of their lives (Collins \& Kay, 2014).

Despite this, sport itself remains a site of social exclusion (Dagkas \& Armour, 2012). Exclusion within and from sport has been specifically conceptulized as a process that negatively impacts a person's rights, recognition, resources and/or their opportunity to participate (Spaaij, Magee, \& Jeanes, 2014). It is worth considering exclusion in opposition to inclusion, which 
has been described as the sense of belonging to, participating in, contributing to and accessing sporting activities (Spaaij et al., 2014). In light of this, social exclusion not only involves a lack of opportunties to participate in sport, but can also include experiences of othering in sporting contexts (MacDonald, Pang, Knez, Nelson, \& McCuaig, 2012).

Research examining social exclusion in sport has found that exclusion tends to be mediated by income, gender, (dis)ability, ethnicity and sexuality (e.g., Collins \& Kay, 2014; Goodwin \& Peers, 2012; Kay, 2014). Trends have indicated lower participation rates for any individuals that diverge from the white, middle class, able, heterosexual male norms that pervade sport (Collins, 2008). Many young people are therefore known to experience exclusion from sport. Girls, for example, have reported experiencing exclusion in sport as a result of male dominance and the (re)production of stringent gender expectations (Kay \& Jeanes, 2008). These same gender expectations and the heteronormative masculine ideals that result are known to alienate a great many individuals who do not resonate with them (Wellard, 2006). Inextricably tied up in these ideals are narrow expectations of ability that support goals of competition and aggression (Hay, 2012; Wellard, 2006). Such ideals impact the sporting experiences of a large number of young people, including those experiencing disability (Goodwin \& Peers, 2012). As a final example, income, the focus of the present paper, can influence both young peoples' desire and capacity to participate in sport (Bourdieu, 1991). The findings from this research suggest that a great number of young people experience exclusion both from and within sport and these experiences require further exploration (Collins \& Kay, 2014; Spaiij et al., 2014).

\subsection{Unequal Sporting Chances}

Young people's relationship with sport and the extent to which they experience exclusion are influenced by dominant societal discourses that are (re)produced through sport. As mentioned, sport has a tendency to support the participation of those who fit dominant white, middle class, able, heteronormative, male discourses, while undermining the involvement of those who do not (DePauw, 1997). Neither the amount of sport opportunities nor the profits that can be accrued through sports participation (e.g., a sense of belonging, enjoyment or acclaim) are therefore equally available to all young people (Bourdieu, 1984). In particular, living with a lower income has the potential to undermine the involvement of young people and make the profits of sport more difficult to attain (Collins \& Kay, 2014).

The term "living with a lower income" is used here to describe individuals who have less economic and cultural capital as a result of their income. Not simply an objective categorization, a lower income (a young person's own income or that of their parents) is experienced subjectively, and can influence much broader matters of education, housing, and values (Bourdieu \& Waquant, 2013). Young people who live with lower incomes are known to experience social exclusion from and within sport. As a result, there is an important need to understand the ways sport reproduces these processes of social exclusion so they can be challenged (Spaaij et al., 2014).

\subsection{Participation and Barriers}

Research exists that has begun to explore the exclusion of young people living with lower incomes from sport. However, these studies have largely been limited to concerns about low participation rates (Donnelly, 1993; Spaaij et al., 2014), which have been predominantly attributed to financial "barriers" such as the cost of sports, lack of transportation, and the time commitment necessary to participate (Penney, 2001). Although a useful starting point, this research explains only a small part of a much larger process of social exclusion. Such narrow approaches may also unintentionally and erroneously attribute differences in participation to low motivation when opportunities are provided (e.g., through fee assistance programs) but youth do not participate (Ingham, Chase, \& Butt, 2002). As a consequence, these young people may be labelled as deviant and problematic (MacDonald, 2003; Wright, MacDonald, \& Groom, 2003). A focus on individual attitudes cannot sufficiently explain the ways young people's circumstances intersect with their desires and the opportunities available to them (Wright et al., 2003). Accordingly, drop-out narratives may mask and potentially exacerbate the discourses in sport that privilege the participation of some young people while undermining that of others, making motivations of choice neither a simple (nor equal) proposition.

\subsection{Hidden Requirements in Sport}

Characterizing sport as a level playing field where all young people can aspire to the same goals of participation does not accurately represent the ways sport has the potential to exclude (Evans \& Bairner, 2013). Far from equal, there are hidden requirements for sport engagement that disproportionately impact young people living with lower incomes (Bourdieu, 2010). These hidden requirements go beyond the need for financial resources and involve, among a range of demands, early participation, particular abilities, and appropriate clothing. Rather than consider the experiences of young people as a matter of the individual, there is consequently a need to consider the empirical experiences of young people living with lower incomes within the cultural context of sport (Ingham et al., 2002). By considering the ways in which sport is an unequal play- 
ing field for young people experiencing lower incomes, we can begin to see how they may be impacted by exclusion (Spaaij et al., 2014).

Youth are likely to move in and out of sport at different times in their lives, making exclusion a fluid process rather than a discrete end point (MacDonald, Pang, Knez, Nelson, \& McCuaig, 2012). Evans and Bairner (2013) have recognized the importance of exploring these varied experiences, stating the need to question how sports are "read and received in specific contexts of opportunity, by specific social groups, with specific needs and resources to access them" (p. 152). However, our understanding of the many ways young people living with lower incomes actually experience sport is thus far inadequate (MacPhail, 2012). This is a critical omission given that complete exclusion from sport is an unlikely scenario for most young people (Spaaij et al., 2014). The majority of young people have some experience of sport, whether this occurs casually with friends, in an organized community setting, or at school. Yet our understanding of these experiences remains sparse.

\subsection{Experiences of Young People in Sport}

Although the number of studies exploring the sport experiences of young people living with lower incomes is limited, there are several researchers whose work begins to uncover some of the processes of exclusion that youth might encounter. Coakley and White (1999) interviewed fifty-nine young people (aged between 13$20)$ to understand the decision-making processes that influenced their sport involvement. Approximately three-quarters of the youth were living with lower incomes. The researchers found that young people's participation was indeed influenced by more than only financial constraints. Among other factors, youth spoke about the need for adequate physical skills, in addition to their desire for activities that were not tightly controlled by adults.

As part of a collection of studies, Macdonald et al. (2012) examined the place and meaning of sport for young people. They interviewed Indigenous, Asian and Islamic youth between the ages of 10 and 16 in Australia and Hong Kong. The findings from these interviews suggested that despite participants' desire for inclusion, factors such as cost, geographical dis/location, cultural constraints and racism made participation difficult. The impacts of financial resources in this study were, however, limited to a discussion about cost and transportation as barriers.

Finally, Quarmby and Dagkas (2013) explored the place and meaning of physical activity for young people between the ages of 11 and 14 living with lower incomes in lone-parent families. They found that the availability of financial resources impacted participation in a number of ways, beyond the difficulties associated with cost and transportation. For example, they found that the material conditions of young people's lives influenced the value they placed on physical activity.

These studies offer an important starting point from which to begin understanding the sport experiences of young people who live with lower incomes and the ways in which these experiences may be exclusionary. However, greater exploration of how these young people experience sport is required (MacPhail, 2012). Such research would provide a deeper understanding of the exclusionary practices of youth sport so they can be challenged in relevant and meaningful ways. In the present study we consequently set out to explore the sport experiences of young people living with lower incomes, questioning how sport itself may be implicated as an unequal, differentiating and exclusionary practice. A brief overview of Bourdieu's work is provided to explain how it was used to inform the analysis of data in the study.

\section{Theoretical Framework}

The work of Pierre Bourdieu (1984, 1991, 2010, 2013) was used to inform the analysis of the empirical data and provide a framework for understanding the experiences of young people in sport. Bourdieu's concepts of capital, field and habitus helped to uncover some of the ways in which income influenced young people's experiences of sport, beyond just the availability of financial resources to purchase opportunities.

Sport participation requires a certain amount of both economic capital and cultural capital for youth to gain opportunities for sport and have enjoyable experiences when they do. Economic capital includes not only resources of money but also related privileges such as the availability of spare time. Cultural capital is the profit or privileges that can be gained through the expression of particular ways of being that are valued in a cultural field (Bourdieu, 1984). Cultural capital includes the possession of ability in its broadest sense, i.e., performing in ways that were valued in a sport context. It also results from the possession of values and desires that are aligned with those reproduced in sport. The acquisition of cultural capital in sport and across other fields (e.g., education, family life) occurs at an early age and is influenced by a person's habitus, a system of tastes and preferences that defines the attachment of meaning to social practices (Bourdieu, 1991).

Habitus is strongly influenced by the material conditions of a person's life (Bourdieu, 1984). The habitus of individuals are consequently shaped by the subjective ways they experience their incomes (Bourdieu \& Waquant, 2013). A young person's habitus can shape the ways they attach meaning to sport and influence the extent to which they can acquire cultural capital in a particular field. Because capital is unequally distributed to maintain its value, young people have to com- 
pete for sporting capital with other participants who may have more favourable material conditions for accumulating the profits that are available through sport.

Bourdieu's concepts of capital, field and habitus helped to draw lines between the individual and shared experiences of young people and how these were mediated by their lower incomes. The ways material conditions can shape habitus and contribute to an unequal distribution of capital uncovers some of the ways sport continues to be a site of exclusion for young people living with lower incomes.

\section{Methods}

\subsection{Developing the Research}

The purpose of this study was to understand the sport experiences of young people living with lower incomes. A community-based approach informed the research process to bring together a more diverse set of knowledge and expertise across practice-based and academic contexts (Cargo \& Mercer, 2008). The first author (a university researcher) initiated a partnership between two municipal accessibility coordinators and a youth initiatives coordinator from a provincial recreation association. Partners met 1-3 times per month depending on the stage of the project over a period of two-and-a-half years. The partnership collectively developed the scope of the project, which included the research questions, methods, timelines, responsibilities, goals, and ethics (Israel, Schulz, Parker, \& Becker, 1998). Interpretive Description (Thorne, Reimer Kirkham, \& MacDonald-Emes, 1997) was the method chosen for the project with the intention of generating knowledge that could bridge academic and professional contexts. Relevant literature was drawn upon to provide "scaffolding" through which to ground the study (Thorne, Reimer Kirkham, \& O'Flynn, 2004, p. 5). The design of the research was additionally shaped by the practice-based knowledge provided by the partners (Thorne et al., 1997).

We conducted the research in a community where the Department of Recreation and Culture had introduced fee assistance for recreation for residents experiencing lower incomes (and in which two of the partners worked). Passes were provided that enabled free use of local recreation facilities and a reduced rate on program registration ( $25 \%$ of the original cost). Those who received passes were also referred to other services to reduce barriers to participation, such as the provision of additional funding for equipment, bus passes, and registration in sports programs outside those offered by the Department (e.g., by schools, community leagues, private clubs). We were particularly interested in understanding the experiences of the young people living in the community (between the ages of 13-18) whose parents had received fee assis- tance. According to facility-use records, young people had the lowest participation out of all those who had received assistance and we believed this might have represented a larger pattern of involvement. Parents and children under the age of 13 were comparatively the highest users.

Ethical approval for the project was granted from a University Research Ethics Board during the initial stages of the partnership and a modified ethics proposal was approved once the scope of the project had been determined. Partners additionally engaged in discussions throughout the project about the most appropriate way to conduct the research, reflecting a relational ethics approach (Boser, 2007).

\subsection{Participants}

Given an expressed need in the literature to consult young people about their sport experiences (MacPhail, 2012), we prioritized interviews with young people (between the ages of 13-18) in addition to speaking with parents about the fee assistance they received. The community where the research took place was affluent and predominantly white, with a rapidly growing population of approximately 92,000 residing in the urban centre and surrounding rural areas (Municipal Census Report, 2012). To recruit participants one of the accessibility coordinators sent 150 letters to young people whose families had received fee assistance and consented to being contacted by the Department. To receive fee assistance, the parents of these young people had attended an intake meeting at their local Family and Community Support Services (FCSS) branch and expressed their desire for assistance due to a lack of disposable income (more often than not this was determined by an income cut-off).

In total, 10 young people (13-18 years) and 6 parents participated in either a group or individual interview. All of the parents we spoke with were mothers, five of whom were raising their children as single parents. Single parent in this sense meant that parents were divorced or separated from their partners and were no longer living with them. The extent to which their ex-partners were part of their children's lives varied across families. Two of the three young people interviewed without their parents present shared that their fathers had left home when they were younger. One was also living apart from her mother as a result of alcohol addiction.

The study participants had experienced lower incomes for varying amounts of time. Some of the parents previously had higher incomes and found themselves in newer circumstances as a result of separation, disability, and/or abuse. Other parents and young people had lived with a lower income over a more sustained period of time. The housing circumstances of the families were largely unknown, but two of the in- 
terviews took place in housing cooperatives in the urban centre. In terms of employment, four of the parents worked (one of these women was concurrently pursuing higher education). Two parents experienced disability and could no longer work. As such they received an assured disability income of approximately $\$ 16,200$ annually (compared to the median family income of $\$ 94,460$ in the province) (Statistics Canada, 2012).

The material conditions of the participants' lives are significant in this study because they are understood to shape the habitus of individuals over time. They are thus likely to have influenced the young people's relationship to sport and the extent to which they could accrue cultural capital (Bourdieu \& Waquant, 2013). In terms of participation, only one of the youth participants was continually engaged in structured activity, some moved from program to program in search of positive experiences, and others were not involved in sport at all at the time of the interviews.

\subsection{Data Collection}

The study comprised one individual interview and seven group interviews. Young people could choose to take part in an individual or group interview, with or without their parent. Two interviews were conducted without parents present. There were challenges with the group interviews - for example, one of the parents felt unable to discuss income-related topics in front of her child and waited until she was out of the room to do so. However, the majority of youth stated a preference for a group interview. Youth aged 14 and above were permitted to consent to an interview without the additional consent of a parent, in line with the view that young people have the capacity to make informed decisions about their own interests and consistent with other community-based research approaches (e.g., Flicker \& Guta, 2008; Roddy Holder, 2008).

The interviews took place in a number of locations that included the community library, recreation centres and participants' homes. Interviews were semistructured and as such, an interview guide was used as a foundation from which to ask young people about their experiences of physical activity more generally, a term we felt would best capture the range of young people's experiences and encompassed sport, exercise, and play. Questions asked young people what physical activity meant to them, how important they felt it was to their lives, the nature of their participation, the opportunities available to them, and the extent to which it met their desires. Through these questions, participants often discussed sport-like activities, such as hockey, gymnastics, soccer, dance, and basketball. Follow-up questions were asked to explore these experiences in more depth. Parents were also invited into the discussion about their children's involvement. To avoid insensitivity, questions related to income were not asked unless parents first raised the topic. During the interviews without parents, young people all raised the issue of income themselves. The interviews each lasted approximately one hour and were audio taped and transcribed for analysis.

\subsection{Analysis}

Initial immersion in the data, which comprised numerous readings and re-readings of the transcripts, revealed that youth had multiple experiences of exclusion in and from sport across varying levels and ages. At this stage of the analysis, an iterative approach was adopted in order to navigate between the data and a broad body of literature (Thorne, 2008). For example, social theory was drawn upon to better understand the influence of class relations and how these were working at an individual level while simultaneously working in ways that connected young people through their experiences living with lower incomes. A constant comparative technique was applied to make these relationships more apparent (Thorne et al., 2004). Through this process it became evident that the exclusion experienced in and from sport by young people was closely tied to cultural capital and was mediated by their lower incomes. Bourdieu's work (1984, 1991, 2010, 2013) was drawn upon to inform the remainder of the analysis. In particular the concepts of field, habitus and capital were considered to examine the influence of material circumstances on young people's experiences of sport. Using this lens, the exclusionary practices of sport became more apparent. The data was thus organized into three themes to demonstrate the ways the young people in the study experienced social exclusion in and from sport. These themes are presented below as, The Fundamental Isn't Even There, The Way You're Brought Up, and One of the Worst. Pseudonyms have been used in place of participants' real names to protect their identities.

\section{The Sport Experiences of Young People}

The accounts provided by the participants in the study called attention to the prominent influence of cultural capital on young people's experiences. Ability, as a form of cultural capital, appeared necessary for meaningful involvement. Evans (2004) has described ability as the possession of a range of attributes that are valued in the sport setting. One study participant, Brittany, who was 15 years old, described ability as a particular form of knowledge. She described this in relation to her own capacity to be involved saying, "I would like sports but I don't know how they work. Soccer is the only one I really understand".

Knowing how sports "work" required learning how to engage in a culture in which particular ways of being-dispositions, appearances and actions-were de- 
sired (Hay, 2012). Knowledge was not only about learning the constitutive rules in the setting, it also included knowing how to perform field-specific skills (such as ball-handling skills, offensive strategy, etc.) in addition to performing in less obvious ways (such as conforming to particular sports "etiquette") (Hay \& Hunter, 2006). Without these necessary forms of ability, young people experienced exclusion within and from sport.

Themes were created using the participants' own words and demonstrate the ways young people experienced social exclusion as a result of the demand for particular ways of being in sport. The first theme, The Fundamental Isn't Even There, describes the ways participants perceived the importance of acquiring sporting abilities at an early age for successful participation. The Way You're Brought Up paints a picture of young people's upbringing and the conditions of their existence (Bourdieu, 1984) that influenced their desire to participate in sport and their capacity to acquire cultural capital in order to do so. Finally, One of the Worst describes the experiences of young people when their abilities did not match up to those expected in the field.

\section{The Fundamental Isn't Even There}

This introductory theme offers examples of the ways parents and young people perceived the need to be involved in sport early to shape the fundamental ways of being necessary for participation. Ability served as cultural capital for young people who acquired it, creating a dissonance between those with more capital and those with less. This theme demonstrates the need for ability across varying sporting contexts and is divided by three subheadings: "Dealing with a Four-Year Age Gap", "At the Level of a Six Year Old" and "You Can't Go in As a Newbie".

\subsection{Dealing with a Four-Year Age Gap}

We begin this theme by outlining an example about the need for early involvement in hockey. One of the parents, Julia, recognized that developing sporting abilities in hockey started at a very young age. She recalled her older son's first experiences playing as a child. When Paul was as young as 8 years old she could see the disparity between his abilities and those of the other children on his team. She said,

[Paul] started to play hockey when he was 8. Most people here, because of the affluent society that we live in, have their children already [participating], probably when they're between 3 and 4 ...so you're dealing with a four year age gap. Some of those kids, like I said, started at 4 and he's coming in at 8 and not knowing how to skate. The fundamental isn't even there.
Paul did not have the foundational skills for hockey other peers his age had developed. In this account, Julia acknowledged the role of affluence on early skill development. The availability of economic resources is an obvious facilitator for providing opportunities. Further to this, however, the development of sporting ability is part of a broader process of "concerted cultivation" for middle class parents who tend to have a high level of involvement in their children's lives to ensure they grow up with adequate amounts of cultural capital (Lareau, 2011, p.2). Enrolling children in a variety of activities, including sport, is part of this cultivation process. As a result of the affluent area in which he lived, Paul found himself competing for capital with peers who had been cultivating their sporting abilities from a very young age and across a variety of contexts.

Julia contrasted Paul's experiences to those of her other son, Steven, who began shaping his hockey abilities at an earlier age. She explained, "Steven came in to play hockey at a very young age, so he started in Tom Thumb...[the] youngest level...." Not only did Steven join a hockey team, he was also in a free community program in which families could learn to skate. Julia said, "We enrolled [him] in the 'Can Skate' program. And so that's where he started to, got the technique". She described Steven's skating ability and the impact this had for him in terms of his experiences in hockey: "Steven is much, his fluidity is different, and so, and they saw potential in him, and he was a bigger child, as in stature. And so yeah he did really well". Steven's physicality as a bigger child and the skating fluidity he was able to develop early on were cultural resources that put him on a more equal level with his peers. This cultural capital led Steven to gain recognition from coaches and experience some success in hockey.

\subsection{At the Level of a Six Year Old}

Jacqueline and her mum, Caroline, also recognized the need to acquire particular abilities from an early age to participate in a range of sports. Jacqueline was 13 years old and had been deterred from joining some activities because of a deemed lack of ability. She said, “For a couple of years I haven't joined anything, because I'm not into soccer, and you really have to start at an early age to do gymnastics and hockey and stuff like that...." Discussing gymnastics later in the interview, her mum, Caroline, said, “...for a 14 year old to go in and start gymnastics she would be out of place, cause she'd be at the level of a six year old kind of thing". The acquisition of abilities necessary in gymnastics had not begun early enough for Jacqueline. Learning to perform in these ways was such a concerted process that Jacqueline and her mum perceived there to be no way Jacqueline could enter such a setting with any real expectation of fitting in. Caroline specifically articulated an eight-year gap between the abilities of 
other participants and those of her daughter. Particular ways of being consequently had an age attachment that could be used as an ideological stick against which youth could be measured. Jacqueline described the expectations of ability in gymnastics for someone her age saying, "...the older you are, the harder the program is. I've seen girls my age, they're supposed to learn how to cartwheel on balance beams. I can't even do a cartwheel. So balance beam, cartwheel. No, couldn't do that". As young as 13, the cultural capital necessary to access a gymnastics program were beyond those available to Jacqueline and had been for a number of years.

\subsection{You Can't Go in As a Newbie}

The final aspect of the theme presents Scott's experiences of needing to join particular programs or teams early on in life. Scott, who was 15 years old, perceived this need across a number of contexts. Similar to Jacqueline, Scott chose not to join or try out for certain activities because he believed it would not be a place he belonged based on a lack of acquiring cultural capital early on in that particular field. To make this assessment, he compared himself to other young people he imagined would be in the setting. Discussing a particular BMX club he knew about and had had an interest in joining he said, "...they're extremely organized, very organized. And you can tell that there's kids there that have been there, you know, since they were really little". Scott was able to perceive both the nature of the environment ("extremely organized") and the manner in which cultural capital in such a setting would have been acquired ("since they were really little"). As such, he determined the club was a place he did not belong. Neither Jacqueline nor Scott had actually been in the sport settings they discussed, but had a clear sense of what these settings would entail and the ways they themselves were different from the other participants who attended. Self-exclusion therefore sometimes occurred based on taken-for-granted assumptions about the forms of ability necessary for participation.

Scott also enjoyed playing basketball and spoke about the team at his school. He had chosen not to try out for the team that coming year. He explained his reasoning behind this decision saying,

Yeah there is a team, but unfortunately in grade ten, they're going to pick all the kids that were on the teams in 7, 8, and 9, because again, they want to win. You can't go in as a newbie, and expect to get a spot.

Scott recognized that not playing on the team in previous years would prevent him from being involved at his current age because he had not acquired the cultural capital necessary for participation. Contrary to the previous example in which he had a sense he would not fit in, Scott had been provided a more overt indication that he did not belong on the school basketball team having tried to join during grade 7 without success.

In addition to early and consistent participation, the context in which the refinement of abilities took place also appeared consequential. One sporting environment was not always equal to another when it came to transferring the ability gained in one context into a different context (Bourdieu, 1984). Scott described increasing his soccer ability while playing at lunchtime with friends. He said, "I progressed. What really helped me was, like grade 2, 3, 4 and 5, we always played soccer in the field [at lunchtime]..." Despite acquiring cultural capital in the context of playing soccer at lunchtime with friends, this did not transfer into a different field: "...I got pretty good doing that but never with an actual team". The ways of being that were deemed capital in a casual setting did not necessarily transfer as capital into a more organized setting. This was also evident in the example Scott provided about the "extremely organized" BMX club. Consequently, early involvement in and of itself did not necessarily ensure entry into a range of environments. Instead, early and consistent opportunities to participate across a variety of settings were needed to refine abilities in ways that were valued in a range of contexts. For Scott's soccer, this may have meant early participation in a more organized setting, such as playing on an "actual team".

\section{The Way You're Brought Up}

The following theme illustrates how young people's life circumstances and the ways they were "brought up" impacted their experiences of sport. The theme is divided into three sub-headings-Parental Values, An Issue of Survival, and I Wish I Had Known-to show how the study participants' conditions of existence influenced the meaning they attached to sport and the role it played in their lives. Sylvia, a study participant who was 18 years old, explained how upbringing could influence sport participation saying,

I guess it's all in the way you're brought up. You know, [it] doesn't matter if it's different beliefs, or like just personal preferences. Some people you see come from wealthier families, [they] get to partake in more activities, because they can...

In this articulation, Sylvia highlights the interplay between personal values, material conditions and sport involvement. Beliefs and preferences, such as the value of concerted cultivation, served as cultural capital for some of the young people in the study because they aligned with the values that were reproduced through sport (Bourdieu, 1984). Sylvia, however, appeared to have fewer of these cultural resources than the other study participants. 


\subsection{Parental Values}

Beliefs and preferences, such as the value of concerted cultivation, can serve as cultural capital when they align with the values that are reproduced through sport (Bourdieu, 1984). Parental values and the values they impart on their children can therefore impact a young person's sport participation. Sylvia spoke several times about the ways her parents' values impacted her involvement in sport. She said,

The only team I was ever a part of really was that little softball league....Yeah. I think it, everything just kind of goes hand in hand with everything. Like you know everything just depends on personal values, parental values, how wealthy your family is.

In contrast to many of the other young people in the study, Sylvia's parents did not make concerted efforts to support her involvement in sport. Sylvia's father had left home when she was 11 and her mother was "not sober". As such, Sylvia had not really ever been involved in sport. Although she did not speak too much about the context of her life growing up, she did share that she had been, "on welfare for most of my life". She described her current circumstances, saying

Well my biggest priority right now is helping my boyfriend pay rent. We live together, because [I] can't live with my mum. So we live together and we have to pay rent, and we have to pay the bills, and we have to buy groceries. So in order to do that I have to work, and go to school so that when I'm out of school I can continue going to [university]. And then get a career for myself, because I don't want to have the same disadvantages as my parents, and my sisters, my grandparents and all my friends. I want to have something going for myself. So that's my priority is getting on that path.

Sylvia did not view sport as playing a role in getting her on that path and instead viewed it as a privilege that was available to people who had more wealth. Bourdieu (1984) refers similarly to the tastes of freedom deriving from material conditions that allow a certain distance from necessity. Sylvia's life was not one that allowed such tastes of freedom. Instead it was a life coloured by necessity, with priorities such as working to pay rent and completing high school. Sport did not have a high value-attachment in Sylvia's world and she instead appeared to distance herself from it.

Interestingly, the parents who participated in the study did attach a high value to the role of sport in their children's lives even though their material conditions did not allow much distance from necessity. This may have been a result of living in an affluent community, which put pressure on parents to maintain a particular way of living to avoid stigmatization. In addition, some of the parents discussed having had previously higher incomes. Their changing life circumstances may have therefore resulted in a change in social position that was not necessarily accompanied by a simultaneous shift in values (Bourdieu, 2010). Such incongruence led to difficulties when parents believed in the value of sport participation for their children but did not necessarily have the material conditions to support it. In the following sub-theme, parents describe some of the life circumstances that made concerted participation in a variety of sports generally unattainable for their children.

\subsection{An Issue of Survival}

Two of the parents, Julia and Janet, described the material conditions that pushed sports to the fringes of their lives. Julia had separated from her partner and left with her sons to live in a temporary shelter before moving into the housing cooperative where they were living at the time of the interview. She described their lives at the shelter as a time of survival, during which sport was not a consideration:

You know, like I said, when you were in the environment that we were in, it was an issue of survival, so a lot of people in that scenario, they're not looking at that (opportunities for sport). They are more looking at what's ahead of them, relative to where to live and we were in that situation too.

Trying to find opportunities for her sons to be involved in sport was not a realistic endeavor during this time in their lives.

Janet also spoke about a change in life circumstances that made sport participation for her children extremely difficult. She explained,

I had gone out into the work world and then my son got hurt, which changed everything....And my son was quite young and he needed a lot of, like we were at the hospital, there was a lot of that. So, it was, it's hard to go from like a $\$ 70,000$ paying job, down to like, we were on social assistance for a while. Because it's just the way it was, like we, it was either, I take care of the kids and you know, and one with a handicap and that, and it was just, it was hard. It was a hard adjustment for the family, hard adjustment for me. We were in the middle of a huge lawsuit, so there was nothing, like really literally nothing. Like it was like, we were at the food bank, you know, and we had done that. And I remember there were times... where we didn't have money to put gas in the car, to go across [town], which is not very far...

Even later on when Janet had returned to work, having 
each of her children consistently participating in sport was not a possibility because of the requirements of time associated with involvement. She said, "I'm a single mum, so I find it difficult to try and keep up with my kids schedules all the time. I work with the federal government, so it's like you know, I'm coming home and then it's like you know, going here, going there". Asked if and how it impacted their participation she said,

....I had to cut it down, and I'd have to say to them, okay so one can play at one time, you know, because my boys, when they wanted to play outdoor soccer, they were almost on competing nights, and then there's was one of me and I had to be in two different places. So you'd have to say...okay so, this one [is] your turn to play, your turn to play, your turn, your turn. Because I couldn't keep up to it, you know.

\subsection{Wish I Had Known}

Caroline also explained how her family's life changed and the impact this had on their sport involvement. She described how her two younger children, Tori (12 years) and Jacqueline (14 years), had not had early and consistent opportunities for involvement in sport after separating from her partner. She compared their involvement to her two older children, Carter (19 years) and Mitch (16 years), who had been able to play soccer every year from an earlier age. She said,

I got divorced 4 years, separated 4 years ago, so it was a very different lifestyle. So whereas [Carter] and [Mitch] got to be participating in soccer, outdoor soccer every year, I think [Jacqueline's] gymnastics, all that kind of thing, as of four years ago, and I don't get any financial support, so I'm just living on my salary, I had to go back to work. So money is different.

Caroline spoke about the fee assistance available that could have helped provide earlier opportunities for her daughters. However, not knowing about the many forms of assistance meant that she had only recently applied for funding to support her daughter's involvement. She explained,

...I wish I had known that there were other grants available for things like the outdoor soccer... It would have been really nice to know it, and I guess in hindsight, maybe I should have clued in, but at the time I didn't, at the time [it] was just sort of a whole new sort of world, and what was out there.

Highlighting the significance of lost time in terms of sport participation, she added, "[Tori] is $12 \frac{1}{2}$ now and her brothers started [soccer] when they were 8 ". As indicated by the previous theme, this lost time meant Tori had missed out on the opportunity to acquire the cultural capital necessary to put her in a position to compete with her peers.

At the time of the interview Caroline was waiting to hear whether she had secured the funding necessary for Tori to register on a soccer team. Tori's involvement was dependent on receiving this funding and without it she would not be able to play:

I'm just waiting now to hear back to see if we've been accepted or not, but I really have my fingers crossed because I would love to give the opportunity, she loves soccer....Someone had mentioned that there were grants out there, so I hadn't known beforehand. I wish I did, I wish I had known four years ago, because I would have had her, definitely in that then.

Although fee assistance had the potential to provide sporting opportunities for young people, it could not guarantee early or concerted involvement. Funding was annually determined and required a new application with each new sporting opportunity. Jennifer illustrated the inefficiencies of this process saying,

Yeah it's not always easy to get funding for [participation in sport]. They have $\mathrm{X}$ amount of dollars, depending on how many people have donated, and last year, I was hoping to get him in for the spring session. They didn't have any funding left, so he couldn't play.

Some of the parents were consequently in a continuous cycle of applying for funding to try to initiate and maintain their children's participation in a system that did not guarantee their efforts would pay off. The likelihood of young people having early and consistent involvement in sport over time was extremely slim, if possible at all. Participation, if it did occur, was therefore usually sporadic and occurred in select activities. This led to instances in which young people's abilities in sport were not comparable to those of their peers.

\section{One of the Worst}

This final theme describes young people's experiences with/in sport when their abilities did not match up to those of their peers. This theme is divided into four subheadings - It Just Kind of Ruined It, Didn't Make the Cut, Lumped in and Afraid of What People Would Sayto highlight how young people's conceptions of their (in)abilities were shaped in relation to others and were mediated by the processes of differentiation inherent to sport. 


\subsection{It Just Kind of Ruined It}

This sub-theme highlights how young people's experiences were differently impacted depending on the extent to which there was a focus on performance rather than participation. Joining hockey at the age of 8 , Paul was already four years behind some of his peers in terms of their skill level. Paul recalled his initial experiences playing hockey saying,

Yeah so I started out and I wasn't, I played on like the worst like possible team there was, cause I couldn't skate or do anything, and I didn't do good on that team at all. I was probably one of the worst...

Paul's conceptions about his ability were shaped early and were made in comparison to his peers in the setting. Despite determining that he was one of the worst players on the team, he continued to play: "I just wanted to go and play. I didn't think too much about being bad. I just thought I was part of the team, even though I wasn't doing well". The environment he described may have been one that emphasized participation more than performance, which allowed him not to have to "think too much" about his (in)ability. This changed as he got older and the focus on ability increased: "I did well, and I got better, but that kind of became the end of it, because once you get up there that's where they really, really start to take it serious." To Paul, "up there" was a sporting space that resembled one of seriousness. He spoke about playing at this level, describing parents who "live through their kids..." He also described situations where he "got benched a few times for, I don't know." Summing up the experience he said, "...it just kind of ruined it, eventually." The environment portrayed was one that demanded particular ways of being that Paul was not willing or able to perform.

Processes of differentiation that sorted those with ability and those without were heightened in sporting environments that had narrow conceptions of what it meant to be able. Tina described her daughter's participation in gymnastics when she was younger and how she felt the focus on performance led to her daughter's reduced sense of confidence. She said,

It started to go sour when people put a lot of focus on the technique and not so much the attitude, and how well the child was just willing to participate. It was how well they were perfecting the skill, and they'd focus on that skill and in turn, bring down the child's esteem, instead of just building up their participation. And that really brought down a lot of confidence, in my children, anyway...

Tina believed there should have been a focus on participation rather than the focus on performance that seemed to shape the program.

\subsection{Didn't Make the Cut}

Scott and his mum similarly described the impact of a performance culture on Scott's experiences in school sport. However, in contrast to Paul and Brittany's experiences, the focus on performance prevented his participation entirely. Jennifer spoke about Scott's attempts to make it onto the school basketball team in grade 7 saying, "he tried to make the basketball team at school, but didn't make the cut because they're really competitive". Asked what he thought of the school sport process, Scott said it was "kind of stressful". He highlighted the public nature of the try-outs explaining, "They wrote numbers on our hands. [Then] they would call us up and we'd have to start doing lay-ups and stuff". His mum, Jennifer, recalling the experience, said to Scott, "Do you remember how packed the gym was? Kids were lined up sitting all the way around, and you could tell right away that your kid wasn't going to make it".

Having kids sitting around the perimeter of the gym turned it into something of an amphitheatre, where abilities were put on display for comparison with others. Following the try-outs, Scott described how the names of those who made it onto the team were written on a piece of paper and hung up on a wall at school: "...after that, we just went back to class and they posted up who made it on the team, on a board in front of the gym." Scott was not selected to play on his school team. His mum, Jennifer, expressed her frustration saying, "It's really discouraging to be told before you've gotten started, that you suck". Julia also spoke about this in terms of her own sons' chances of participating in school activities. She said, “...you're limited because they're only going to pick [the best] for these [school] teams...so if you're not the best at it, what is available for you in the school?" The selection of the "best" players and the lack of availability of alternative options that existed for young people when they were not deemed able enough were reasserted by Scott's mum, who said,

That school has got to win, so they just take the top people. Where do they go? What do they do? That's really not encouraging kids to play, it's encouraging kids to compete and win. And there's got to be a place for everybody else.

In the following sub-theme, Tina described what such a "place for everybody else" had looked like for her daughter, Brittany, when she participated in gymnastics.

\subsection{Lumped In}

Lumped in provides an example illustrating how not being fully excluded from sport did not prevent exclusion within sport (Spaaij et al., 2014). Tina described her daughter, Brittany's, experiences in a gymnastics pro- 
gram that grouped participants according to ability rather than age. She had been involved in gymnastics inconsistently growing up and had not developed the same abilities as other young people her age. As a result, Brittany was placed in a group with much younger children. Tina explained,

I found room in the budget to put her in gymnastics but her skill level is deemed to be at sort of a beginner level, where it should be at the age of 14 ...she was lumped in with 5 and 6 year olds, which just does not work. So then that money was sort of just thrown out the window, because she wasn't comfortable being in a group of younger children.

The message conveyed about Brittany's ability by her placement in a program with young children was made extremely clear to her and the other participants: she did not measure up against the standards expected for her age. Not surprisingly, she chose to stop participating in the program. This account additionally highlighted how decisions about young people's sport participation involved a necessary process of weighing the costs against the potential profits of involvement. In this instance, the financial cost had greatly outweighed any benefits and money was deemed to have been "thrown out the window". This paints a picture of how the availability of disposable income (or lack thereof) can impact decisions about sport participation.

\subsection{Afraid of What Other People Would Say}

As a social setting, the other participants in sport largely influenced the experiences of the young people in the study. The presence of peers provided a measuring stick for comparisons of ability and comprised an audience with the potential to judge. As mentioned previously, Sylvia's relationship to sport was one that had ended quite early in her life. She explained what she believed to be the main reason for not participating saying, "[My] biggest holdback (from joining sport) was I was afraid of what other people would say. I think a lot about what other people are thinking about me". Not fitting in and the fear of judgement made sport a setting in which Sylvia perceived she would have little capital. Describing the impact of this she said, "Being self-conscious, like feeling not as good as you could".

Sylvia described an alternative setting in which she felt she did belong. She had been involved in the army cadets until four years prior to the interview. She described how she felt in that particular environment saying, “...I just, I loved it. I love the people, I love you know, going out on trips. I liked all the different activities they were having us do, and the discipline. I don't know, that's weird to say, but I liked the discipline".

Sylvia went on to say that cadets represented the "type of person I am". Asked further about this she spoke about perceiving differences between her own ways of being and those of other girls that played sports, who she described as "blonde" and "preppy". The use of the term "preppy" to describe young people who participate in sport demonstrated the association Sylvia made between sport involvement and the availability of wealth. Sylvia viewed sport, or at least the sports that might be available in her community, as a symbolic expression of a class position that did not match her own (Bourdieu \& Waquant, 2013). Preppy children are considered those who are cultivated, or prepared, for their futures in a very deliberate manner, such as through involvement in sport. Sylvia distanced herself from this culture and related instead to cadets. She said, "That's why I felt like I belonged in a more masculine environment, because this is the way I am". Cadets provided a stark contrast from sport and a place that more closely represented who Sylvia was and the material conditions of her life.

\section{Discussion}

Sport is often hailed for its capacity to promote a sense of belonging and mitigate processes of social exclusion that may be experienced in other areas of life (Collins \& Kay, 2003; Dagkas \& Armour, 2012). However, sport itself remains a site in which young people living with lower incomes face exclusion (Collins \& Kay, 2014). Although structural barriers to sport have been well documented for youth living with lower incomes, this body of research explains only a small part of a much larger process of exclusion (Wright et al., 2003). As such, further research was required to understand the social exclusion of young people living with lower incomes in sport.

This study sought to further understand the ways sport reproduces processes of social exclusion so they can be challenged (Spaaij et al., 2014). The following discussion considers the ways the study participants experienced exclusion in relation to sport and how these forms of exclusion reflected or departed from those reported in the existing literature.

Previous studies exploring the sport experiences of youth living with lower incomes have predominantly focused on low participation rates and the need for more widely available opportunities for sport (Donnelly, 1993; Spaaij et al., 2014). The youth in the study did indeed struggle to gain sporting opportunities as a result of their limited financial resources, which impacted the availability of time, transportation and money for participating. Fee assistance programs such as the one implemented by the Recreation Department in the current study offset some of these financial-related barriers to increase opportunities for sport (Frisby et al., 2005).

Despite this, young people's exclusion resulted from more than simply a lack of opportunities. Their experiences demonstrated that the nature of these 
opportunities was also important. Realistically, youth needed early, concerted and consistent opportunities in particular sporting contexts to develop the necessary abilities to compete with their peers and develop a sense of belonging. However, the material circumstances of their lives made this form of involvement largely impossible. Although fee assistance provided sporadic opportunities for sport, funding was annually determined and therefore rarely supported continuous participation. Increasing the availability of opportunities, as has been advocated for in previous literature (e.g., Dagkas \& Stathi, 2007), is unlikely to make sport less exclusionary as long as such narrow demands for ability exist (Hay, 2012). To acquire these forms of ability requires a process of concerted sporting cultivation that was neither achievable nor desirable to most of the young people in the study.

It is also worth highlighting that the processes of exclusion in this study went beyond only the need for ability and were part of a broader demand for cultural capital in sport. The material conditions of the participants' lives shaped each young person's habitus, including their values and desires (Bourdieu, 2010). When a young person's habitus was inconsistent with a particular sporting context, they tended not to have the capital necessary for a sense of belonging in that field. Sylvia, for example, found sports to be "preppy" and avoided them. Scott was deterred from joining a BMX club because he suspected it was "highly organized". These examples demonstrated how some sporting fields did not resonate with the young people in the study and support the suggestion that sporting tastes can be shaped by class (Bourdieu, 2010; Quarmby \& Dagkas, 2013). When considered in light of the structural barriers that existed to inhibit involvement, young people were unlikely to make a concerted effort to join activities in which they had already assessed they would not fit. This demonstrates the intersection that occurs between the costs of involvement associated with structural constraints and the available profits or capital that young people could accrue. Without the profits of fitting in and feeling a sense of belonging, overcoming the structural barriers of cost, time and transportation, if at all possible, were simply not worth it.

As a final consideration, the community in which the young people resided was also of particular consequence in relation to the exclusion they experienced in sport. Returning to Lareau's work (2011), the demand for and distribution of cultural capital appeared especially disparate in an affluent community in which a philosophy of concerted cultivation seemed to pervade. Although the parents in the study valued the role of sport in their children's lives and tried to orchestrate as many opportunities as they could, the sporting peers of the youth in the study would likely have had more opportunities than most to acquire cultural capital. This pushed the cultural capital bar even further beyond the reach of the youth in the study than it may have been in a less affluent environment. The context is thus largely significant when considering processes of exclusion in future research.

\section{Conclusions}

The present study sought to explore the sport experiences of young people living with lower incomes to further understand the processes of social exclusion that exist in sport so they can be challenged in relevant and meaningful ways (Spaaij et al., 2014).

The participants in the study provided some examples of the exclusionary processes that are apparent in sport. Structural barriers, such as the demand for money, time and transportation impacted the young people's involvement. Additionally, youth experienced exclusion because they did not have comparable reserves of cultural capital to other participants in sport. This demand for cultural capital included the need for particular abilities, values and desires that were celebrated in the various sporting fields.

As such, without reserves of economic and cultural capital, young people experienced exclusion in a number of ways. They were denied entry into sport, had less-than-meaningful experiences within sport, or they made choices not to participate. It is clear from their experiences of not belonging that exclusion occurs both outside of and within sport (Spaiij et al., 2014). It is also evident that gaining access to sport does not necessarily ward off other experiences of exclusion (Goodwin \& Peers, 2012). Although fee assistance programs provide increased opportunity for sport, they alone are not enough to alleviate social exclusion because of a broader demand for capital that is unequally distributed along class lines. Further, the presence of fee assistance programs might serve to neutralize attempts to challenge the more deeply rooted processes of exclusion that impact the sport experiences of young people living with lower incomes if their limitations are not acknowledged (Jarvie, 2012).

At times, the sports available in the community did not resonate with the young people in the study. Youth often felt they did not belong in these environments and the costs of participating tended to outweigh the profits. As a result they had little desire to pursue sporting opportunities or were deterred from joining. Although a form of self-exclusion, these choices were tied up with the material conditions of young peoples' lives (MacDonald et al., 2012). As Evans (2004) has highlighted, "class does not just determine choice and preference in sport. It also determines a person's physical capacity, 'their ability' to realize those choices and preferences, let alone extend them" (p.102). The nature of choice is not therefore straightforward and blurred lines exist between self-exclusion and enforced exclusion (Spaaij et al., 2014).

To conclude, the purpose of this study was to further 
understand the ways sport reproduces processes of social exclusion so they can be challenged (Spaaij et al., 2014). The findings of the study demonstrate the interlaced nature of the exclusionary processes in sport that impact young people living with lower incomes. The material circumstances of participants' lives intertwined with the availability of economic and cultural capital, in turn shaping the extent to which young people felt they "fit" within sport. Cultural capital was not only acquired through sporting opportunities, but was also influenced by upbringing and family values. Exclusion cannot therefore be fully understood in terms of the availability of financial resources or opportunities for sport. Further research about the sport experiences of young people should consequently consider influences of income or class in much broader terms (Bairner, 2007).

In addition, practice-based initiatives intended to make sport less exclusionary should aim to strive beyond the provision of fee assistance and start to challenge the various ways sports privilege a few young people over a great many others. Although situated in terms of income, the exclusionary processes highlighted in the present study are likely to impact more than only young people living with lower incomes. The same narrow expectations defining what it means to be "able" in sport are known to negatively impact those who experience disability (Goodwin \& Peers, 2012), those who do not conform to heteronormative ideals (Wellard, 2006), or any young person who performs in ways that are not celebrated in a sporting field. The structures and goals of sport therefore need to be redefined to meet the desires and celebrate the strengths of a wider range of youth.

In order to confront some of the identified exclusionary processes, the power structures that comprise largely unacknowledged scaffolding in sport should be challenged (MacDonald, 2003). Sport must also be reimagined. This will require new ways of thinking to find solutions that acknowledge the complex and interrelated processes that maintain exclusion. In such a scenario, young people would not be conditioned in normalizing ways to fit the dominant structures of sport (Shogan, 1998; Spade, 2012). Instead, these sport communities would disrupt the narrow hegemonic discourses that continue to exclude a great number of young people. Rather than asking the question, "Would you like to play our game", this version of sport would be grounded in the alternative reflection, "This game is not working. Are you interested in creating a new one?"

\section{Acknowledgements}

We extend our sincere thanks to the study participants for sharing their time, knowledge and experiences. We also thank the project partners for their contributions throughout.

\section{Conflict of Interests}

This paper has been prepared as partial fulfillment of a Ph.D. dissertation (in progress).

\section{References}

Bairner, A. (2007). Back to basics: Class, social theory, and sport. Sociology of Sport Journal, 24, 20-36.

Boser, S. (2007). Power, ethics and the IRB: Dissonance over human participant review of participatory research. Qualitative Inquiry, 13(8), 1060-1074.

Bourdieu, P. (1984). Distinction: A social critique of the judgement of taste (R. Nice, Trans.). Cambridge, MA: Harvard University Press.

Bourdieu, P. (1991). Sport and social class. In C. Mukerji \& M. Shudson (Eds.), Rethinking popular culture: Contemporary perspectives in cultural studies (pp. 357-373). Berkeley, CA: University of California Press.

Bourdieu, P. (2010). Distinction: A social critique of the judgement of taste. In D. Karen \& R. E. Washington (Eds.), The sport and society reader (pp. 55-63). New York, UK: Routledge.

Bourdieu, P., \& Waquant, L. (2013). Symbolic capital and social classes. Journal of Classical Sociology, 13(2), 292-302.

Cargo, M., \& Mercer, S. L. (2008). The value and challenges of participatory research: Strengthening its practice. Annual Review of Public Health, 29, 325350.

Coakley, J. \& White, A. (1999). Making decisions: How young people become involved and stay involved in sports. In J. Coakley \& P. Donnelly (Eds.), Inside sports (pp.69-78). New York, NY: Routledge.

Collins, M. F. (2008). Social exclusion from sport and leisure. In B. Houlihan (Ed.), Sport and society: A student introduction (2nd ed.) (pp. 77-105). Thousand Oaks, CA: Sage.

Collins, M. F., \& Kay, T. (2003). Sport and social exclusion. New York, NY: Routledge.

Collins, M. F., \& Kay, T. (2014). Sport and social exclusion (2nd ed.). New York, NY: Routledge.

Dagkas, S., \& Armour, K. (2012). Introduction. In S. Dagkas \& K. Armour (Ed.), Inclusion and exclusion through youth sport (pp. 1-6). New York, NY: Routledge.

Dagkas, S., \& Stathi, A. (2007). Exploring social and environmental factors affecting adolescents' participation in physical activity. European Physical Education Review, 13(3), 369-384.

DePauw, K. P. (1997). The (in)visibility of disAbility: Cultural contexts and "sporting bodies". Quest, 49, 416-430.

Donnelly, P. (1993). Democratization revisited: Seven theses on the democratization of sport and active leisure. Society and Leisure, 16(2), 413-434. 
Evans, J. (2004). Making a difference? Education and "ability" in physical education. European Physical Education Review, 10(1), 95-108.

Evans, J., \& Bairner, A. (2013). Physical education and social class. In G. Stidder \& S. Hayes (Eds.), Equity and inclusion in physical education and sport (2nd ed.) (pp.141-158). New York, NY: Routledge.

Flicker, S., \& Guta, A. (2008). Ethical approaches to adolescent participation in sexual health research. Journal of Adolescent Health, 42(3), 3-10.

Frisby, W., Alexander, T., Taylor, J., Tirone, S., Watson, C., Harvey, J., \& Laplante, D. (2005). Bridging the recreation divide: Listening to youth and parents from low income families across Canada, Ottawa: Developed for the Canadian Parks and Recreation Association (CPRA).

Goodwin, D., \& Peers, D. (2012). Disability, sport and inclusion. In S. Dagkas \& K. Armour (Eds.), Inclusion and exclusion through youth sport (pp. 186-202). New York, NY: Routledge.

Hay, P. J. \& Hunter, L. (2006). "Please Mr Hay, what are my poss(abilities)?": Legitimation of ability through physical education practices. Sport, Education and Society, 11(3), 293-310.

Hay, P. J. (2012). Ability as an exclusionary concept in youth sport. In S. Dagkas \& K. Armour (Eds.), Inclusion and exclusion through youth sport (pp. 87-99). New York, NY: Routledge.

Ingham, A. G., Chase, M. A., \& Butt, J. (2002). From the performance principle to the developmental principle: Every kid a winner? Quest, 54, 308-331.

Israel, B. A., Schulz, A. J., Parker, E. A., \& Becker, A. B. (1998). Review of community-based research: Assessing partnership approaches to improve public health. Annual Review of Public Health, 19, 173202.

Jarvie, G. (2012). Sport, new social divisions, and social inequality. In S. Dagkas \& K. Armour (Eds.), Inclusion and exclusion through youth sport (pp. 186-202). New York, NY: Routledge.

Kay, T., \& Jeanes, R. (2008). Women, sport and gender inequity. In B. Houlihan, Sport and society: A student introduction (2nd ed.) (pp. 130-154). Thousand Oaks, CA: Sage.

Kay, T. (2014). Gender, sport and social exclusion. In M. F. Collins \& T. Kay (Eds.), Sport and social exclusion (pp. 90-106). New York, NY: Routledge.

Lareau, A. (2011). Unequal childhoods: Class, race, and family life (2nd ed.). Berkeley, CA: University of California Press.

Levitas, R., Pantazis, C., Fahmy, E., Gordon, D., Lloyd, E., \& Patsios, D. (2007). The multidimensional analysis of social exclusion. Bristol: University of Bristol.

MacDonald, I. (2003). Class, inequality and the body in physical education. In S. Hayes \& G. Stidder (Eds.), Equity and inclusion in physical education and sport:
Contemporary issues for teachers, trainees and practitioners (pp. 170-185). New York, NY: Routledge.

MacDonald, D., Pang, B., Knez, K., Nelson, A., \& McCuaig, L. (2012). The will for inclusion: Bothering the inclusion/exclusion discourses of sport. In S. Dagkas \& K. Armour (Eds.), Inclusion and exclusion through youth sport (pp. 9-23). New York, NY: Routledge.

MacPhail, A. (2012). Young people's voices in sport. In S. Dagkas \& K. Armour (Eds.), Inclusion and exclusion through youth sport (pp. 141-154). New York, NY: Routledge.

Penney, D. (2001). Equality, equity and inclusion in physical education and school sport. In A. Laker (Ed.),Sociology of sport and physical education (pp. 110-128). New York, NY: Taylor and Francis.

Quarmby, T., \& Dagkas, S. (2013). Locating the place and meaning of physical activity in the lives of young people from low-income, lone-parent families. Physical Education and Sport Pedagogy, 18(5), 459-474.

Roddy Holder, A. (2008). Research with adolescents: Parental involvement required? Journal of Adolescent Health, 42(3), 1-2.

Shogan, D. (1998). The social construction of disability: The impact of statistics and technology. Adapted Physical Activity Quarterly, 15, 269-277.

Spaaij, R., Magee, J., \& Jeanes, R. (2014). Sport and social exclusion in global society. New York, NY: Routledge.

Spade, D. (2012). Normal life: Administrative violence, critical trans politics and the limits of law. Cambridge, MA: South End Press.

Statistics Canada. (2012). Median total income by family type, by province and territory. Retrieved from http://www.statcan.gc.ca/tables-tableaux/sumsom/l01/cst01/famil108a-eng.htm

Thorne, S. E. (2008). Interpretive description. Walnut Creek, CA: Left Coast Press.

Thorne, S., Reimer Kirkham, S. R., \& MacDonald-Emes, J. (1997). Focus on qualitative methods. Interpretive description: A noncategorical qualitative alternative for developing nursing knowledge. Research in Nursing \& Health, 20(2), 169-177.

Thorne, S., Reimer Kirkham, S., \& O'Flynn-Magee, K. (2004). The analytic challenge in interpretive description. International Journal of Qualitative Methods, 3(1), 1-11.

Wellard, I. (2006). Able bodies and sport participation: Social constructions of physical ability for gendered and sexually identified bodies. Sport, Education and Society, 11(2), 105-119.

Wright, J., MacDonald, D., \& Groom, L. (2003). Physical activity and young people: Beyond participation. Sport, Education and Society, 8(1), 17-33. 


\section{About the Authors}

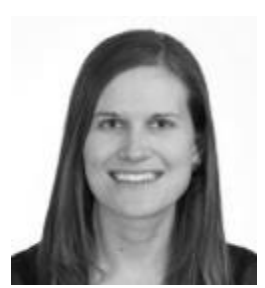

\section{Bethan C. Kingsley}

Bethan C. Kingsley is a Doctoral Candidate in the Faculty of Physical Education and Recreation at the University of Alberta. Using community-based approaches, her research seeks to understand and challenge marginalizing practices that are reproduced through physical activity, sport, and recreation.

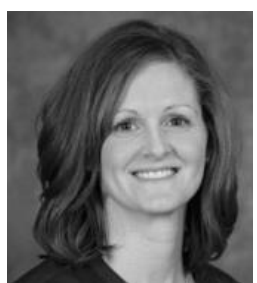

\section{Dr. Nancy Spencer-Cavaliere}

Nancy Spencer-Cavaliere is an Assistant Professor in the Faculty of Physical Education and Recreation at the University of Alberta. Her research interests include understanding social issues related to the inclusion of people who experience disability in the contexts of physical activity, sport, and recreation. 